\title{
Disease burden of COPD in China: a systematic review
}

This article was published in the following Dove Press journal: International Journal of COPD

\section{Bifan Zhu' \\ Yanfang Wang ${ }^{2}$ \\ Jian Ming ${ }^{3}$ \\ Wen Chen ${ }^{4}$ \\ Luying Zhang ${ }^{4}$}

'Shanghai Health Development Research Center, Shanghai Medical Information Center, Shanghai, China;

${ }^{2}$ The First Affiliated Hospital of Wannan Medical College, Wuhu, China; ${ }^{3} \mathrm{QVVIA}$, Shanghai, China; ${ }^{4}$ School of Public Health, Fudan University, Shanghai, China
Correspondence: Wen Chen; Luying Zhang

School of Public Health, Fudan University No. 130 Dongan Road, Xuhui District,

Shanghai 200032, China

Tel +86 I38 I832 5468;

+8618001864003

Email wenchen@fudan.edu.cn;

zhangluying@fudan.edu.cn

\begin{abstract}
Chronic obstructive pulmonary disease (COPD) is one of the main contributors to the global burden of disease. The aim of this systematic review was to quantify the disease burden of COPD in China and to determine the risk factors of the disease. The number of studies included in the review was 47 with an average quality assessment score of 7.70 out of 10. Reported COPD prevalence varied between $1.20 \%$ and $8.87 \%$ in different provinces/cities across China. The prevalence rate of COPD was higher among men (7.76\%) than women $(4.07 \%)$. The disease was more prevalent in rural areas $(7.62 \%)$ than in urban areas $(6.09 \%)$. The diagnostic rate of COPD patients in China varied from $23.61 \%$ to $30.00 \%$. The percentage of COPD patients receiving outpatient treatment was around $50 \%$, while the admission rate ranged between $8.78 \%$ and $35.60 \%$. Tobacco exposure and biomass fuel/solid fuel usage were documented as two important risk factors of COPD. COPD ranked among the top three leading causes of death in China. The direct medical cost of COPD ranged from 72 to 3,565 USD per capita per year, accounting for $33.33 \%$ to $118.09 \%$ of local average annual income. The most commonly used scales for the assessment of quality of life (QoL) included Saint George Respiratory Questionnaire, Airways Questionnaire 20, SF-36, and their revised versions. The status of QoL was worse among COPD patients than in non-COPD patients, and COPD patients were at higher risks of depression. The COPD burden in China was high in terms of economic burden and QoL. In view of the high smoking rate and considerable concerns related to air pollution and smog in China, countermeasures need to be taken to improve disease prevention and management to reduce disease burdens raised by COPD.
\end{abstract}

Keywords: COPD, burden of disease, systematic review

\section{Introduction}

Chronic obstructive pulmonary disease (COPD) refers to a progressive deterioration of lung function and a series of mental and physical comorbidities. ${ }^{1}$ It is one of the main contributors to the global burden of disease. COPD has caused significant morbidity and mortality especially in developing countries. There are also excessive health resource consumption and health expenditures attributed to COPD worldwide. Researchers have found greater burden of COPD in China than in developed countries. In 2008, COPD was known as the fourth and third leading cause of death in urban and rural areas in China, respectively. ${ }^{2}$ There is big variation in the reported prevalence of COPD among different geographic areas in China, which is partly due to different levels of exposure to risk factors and disparities in socioeconomic development among different areas. $^{3}$ Despite the abundant information on the epidemiological impact of COPD, there is limited evidence on its economic influence. ${ }^{4}$ Hence, in-depth study on the disease burden of COPD is still an urgent need. 
The aim of this systematic review was to quantify the disease burden of COPD in China and to determine the risk factors of the disease. Data on prevalence, consultation rate, risk factors, mortality, disease burden, cost of illness, and quality of life (QoL) are extracted from available studies and analyzed to improve public awareness of COPD.

\section{Methods}

\section{Literature search}

A systematic review was conducted to identify articles regarding disease burden of COPD in mainland China in both Chinese and English published before October 2015. The literature search was carried out in electronic databases such as CNKI, Wanfang Data, VIP, PubMed, Embase, and Cochrane. The search terms were as follows: "COPD", "cost", and "health care costs". With CNKI and PubMed as examples, the retrieval strategies are shown in Box 1. Duplicate studies were identified and removed by using NoteExpress.

\section{Study selection}

Publications identified from the first round of search were reviewed by title and abstract independently by two investigators (BZ and $\mathrm{YW}$ ). The inclusion and exclusion criteria used for study selection are listed in Table 1.

\section{Methodological quality assessment}

The quality of the studies was assessed by using a selfestablished scale based on Agency for Healthcare Research and Quality Assessment Form, ${ }^{5}$ the Newcastle-Ottawa

\section{Box I Examples of retrieval strategy}

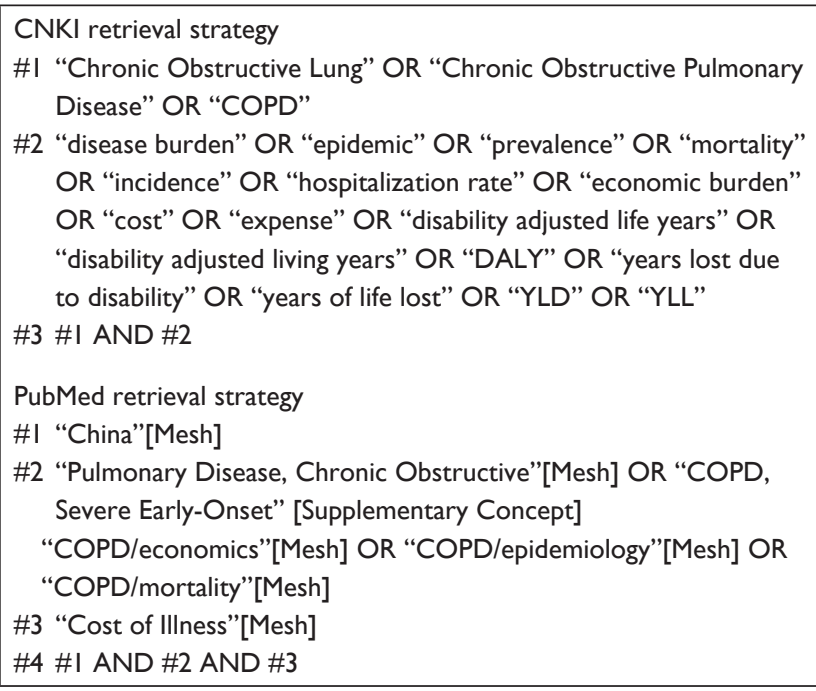

Table I Inclusion and exclusion criteria

\begin{tabular}{ll}
\hline Inclusion criteria & Exclusion criteria \\
\hline - Chinese or English & - Conference abstracts, case reports, letters, \\
language & comments, editorials, and review papers \\
- Full-text available & - Economic evaluation studies on therapies \\
- Studies that consider & - Epidemiological studies on pathogenesis \\
the disease burden & or etiology \\
or quality of life of & - Intervention studies \\
COPD & - Clinical studies \\
& - Effect studies \\
& - Animal or in vitro studies \\
\hline
\end{tabular}

Scale, ${ }^{6}$ and Drummond Criteria ${ }^{7}$ (Table 2). The studies were assessed independently by two reviewers (BZ and JM). The assessment scores were then confirmed and pooled together. Quality score was in the range of $0-10$ points, and the articles were categorized into three classes. Articles with $\geq 8$ points were listed under category A, 4-7 points under category B, and $<4$ points under category $\mathrm{C}$. This study excluded studies with poor quality, that is, those in category $\mathrm{C}$.

\section{Data extraction}

A standardized data extraction form was used to obtain data from research studies included in the final review, including article name, journal of publication, authors, institution of study, year of publication, study design, region of study, study duration, data source, sample characteristics (population and age), prevalence, incidence, influencing factors, consultation rate, mortality, disability-adjusted living years (DALY), years of life lost (YLL), years lost due to disability (YLD), QoL, the scale used for QoL assessment, direct medical cost (yuan per capita, per year), direct medical cost (per capita, per year) \#\% of income per year, direct non-medical cost (yuan per capita, per year), direct nonmedical cost (per capita, per year) \#\% of income per year, indirect cost (yuan per capita, per year), indirect cost (per capita, per year) $\# \%$ of income per year, total disease cost

Table 2 Quality assessment scale

I. Was the objective clear?

2. Was the data source official?

3. Was the study population-based?

4. Was the sampling randomized?

5. Was the study region nationwide?

6. Were the diagnostic criteria clear?

7. Were the results comparatively analyzed?

8. Did outcome indicators include DALY/YLL/YLD?

9. Can the results be externalized?

Notes: All items have two possible answers except number 9: yes $(+)$ and no $(-)$. Item 9 has three possible responses: yes $(++)$, likely $(+)$, and no $(-)$.

Abbreviations: DALY, disability-adjusted living year; YLL, years of life lost; YLD, years lost due to disability. 
(yuan per capita, per year), outpatient expenditure (yuan per capita, per time), hospitalization expenses (yuan per capita, per time), total disease cost of \#\% total health expenditure, and main reason for cost/influence factors.

\section{Results}

\section{Literature search}

The process and results of literature screening are shown in Figure 1. Of all the articles assessed by the quality assessment scale, six were recognized as low quality and excluded from the research (Table S1). The number of articles included in the review is 47: 14 in English and 33 in Chinese, with an average quality assessment score of 7.70 out of 10 . The years of publication of the included studies range from 2002 to 2015. About half of the papers (24 out of 47) were published in 2011 or later. Of the 47 studies identified in the literature review,
15 are about prevalence, 14 about QoL, nine about DALY/ YLL/YLD, and 18 about economic burden (Table 3).

\section{Burden of disease Prevalence}

A total number of 13 studies are engaged in quantitative analysis of prevalence (Table 4). The overall prevalence of COPD in China ranges from $1.20 \%$ to $8.87 \%$, with an average of $5.87 \%$. The prevalence rate of COPD is significantly lower in research studies including population aged $<35$ years, in consistent with the finding that the prevalence rate of COPD rises with the age of certain population segmentation. ${ }^{44,53}$ An overall trend is that the prevalence rate of COPD is higher among men (7.76\%) in comparison with women (4.07\%) and that the disease is more prevalent in rural areas $(7.62 \%)$ than in urban areas $(6.09 \%)$.
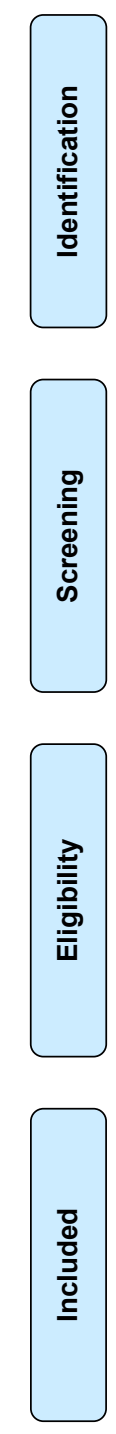
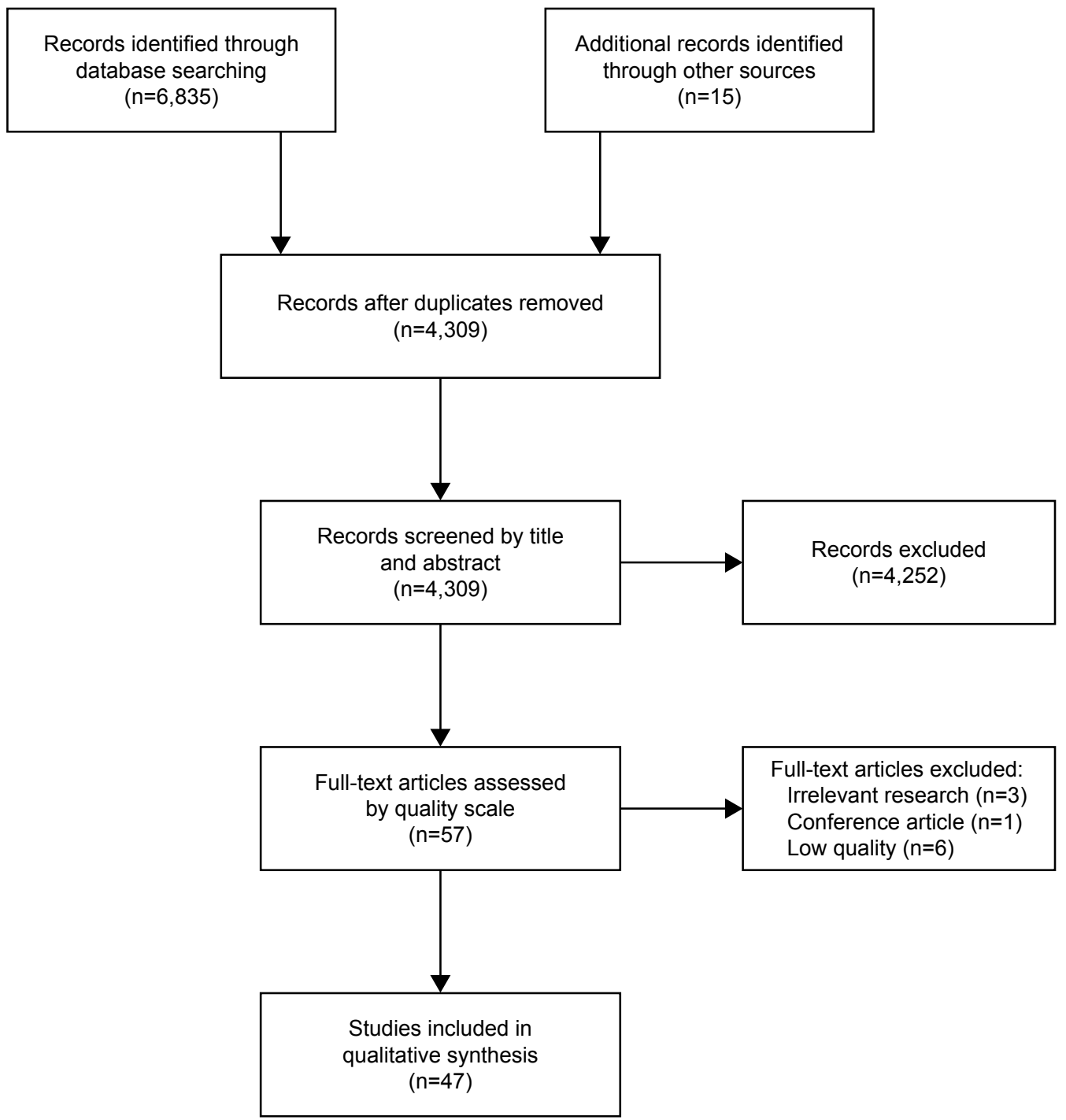

Figure I The process and results of literature screening. 
Table 3 Characteristics of included studies $(n=47)$

\begin{tabular}{|c|c|c|c|c|c|c|c|}
\hline Study & $\begin{array}{l}\text { Publication } \\
\text { year }\end{array}$ & Region of study & Data source & $\begin{array}{l}\text { Sample } \\
\text { size }\end{array}$ & $\begin{array}{l}\text { Sample } \\
\text { age (years) }\end{array}$ & $\begin{array}{l}\text { Indicator of disease } \\
\text { burden }\end{array}$ & Language \\
\hline Yin et $\mathrm{al}^{10}$ & 2015 & China & Official statistics & & $>15$ & $\begin{array}{l}\text { Prevalence, mortality, DALY, } \\
\text { YLL, YLD }\end{array}$ & Chinese \\
\hline Han et al" & 2015 & Heilongjiang & Survey & 4,478 & $>40$ & Prevalence, influencing factors & Chinese \\
\hline Shi et al ${ }^{12}$ & 2015 & Ningbo, Zhejiang & Institutional data & 803 & $>60$ & Direct cost & Chinese \\
\hline Huang ${ }^{13}$ & 2015 & Beijing & Institutional data & 1,638 & $73.4 \pm 9.07$ & Direct cost & Chinese \\
\hline Chen and Bian ${ }^{14}$ & 2015 & Zhuji, Zhejiang & Survey & 82 & $36-81$ & QoL & Chinese \\
\hline Zhu et $\mathrm{al}^{15}$ & 2014 & Xinjiang & Survey & 2,874 & $>35$ & Prevalence, influencing factors & Chinese \\
\hline Cai et al ${ }^{16}$ & 2014 & Yunnan Province & Survey & 17,158 & $>18$ & $\begin{array}{l}\text { Prevalence, influencing factors, } \\
\text { direct \& indirect cost }\end{array}$ & English \\
\hline$X u$ et $a^{17}$ & 2013 & Chengdu, Sichuan & Survey & 83 & $54-86$ & Direct \& indirect cost & Chinese \\
\hline Zhu et $\mathrm{al}^{18}$ & 2013 & Jinshan, Shanghai & Institutional data & & & Mortality, YLL & Chinese \\
\hline An et $\mathrm{al}^{19}$ & 2013 & Beijing & Survey & 97 & & QoL & Chinese \\
\hline Fang et $\mathrm{al}^{20}$ & 2013 & Shanghai & Survey & 101 & 76.15 & QoL & Chinese \\
\hline Jiang ${ }^{21}$ & 2013 & Guangzhou, Guangdong & Survey & 278 & $67.6 \pm 8.0$ & QoL & Chinese \\
\hline Yang et $\mathrm{al}^{22}$ & 2013 & China & GBD2010 & & & Mortality, DALY, YLL, YLD & English \\
\hline $\mathrm{Qiu}^{23}$ & 2012 & Ningxia & Survey & 4,626 & $>40$ & $\begin{array}{l}\text { Prevalence, influencing factors, } \\
\text { consultation rate }\end{array}$ & Chinese \\
\hline Mao et $\mathrm{al}^{24}$ & 2012 & Yunnan (rural) & Survey & 9,396 & $\geq 18$ & $\begin{array}{l}\text { Prevalence, mortality, DALY, } \\
\text { direct \& indirect cost }\end{array}$ & Chinese \\
\hline $\mathrm{Li}^{25}$ & 2008 & Guangzhou, Guangdong & Survey & 102 & $38-83$ & QoL & Chinese \\
\hline $\mathrm{He}$ et $\mathrm{al}^{26}$ & 2012 & Huaian, Jiangsu & Survey & 185 & $\geq 60$ & QoL & Chinese \\
\hline Lou et $\mathrm{al}^{27}$ & 2012 & Xuzhou, Jiangsu & Survey & 5,900 & $40-75$ & $\begin{array}{l}\text { Influencing factors, YLL, QoL, } \\
\text { direct \& indirect cost }\end{array}$ & English \\
\hline Lou et $\mathrm{a}^{28}$ & 2012 & Xuzhou, Jiangsu & Survey & 8,217 & $36-84$ & $\begin{array}{l}\text { Consultation rate, YLL, direct \& } \\
\text { indirect cost }\end{array}$ & English \\
\hline$X u$ et $a^{29}$ & 2011 & China & Survey & 1,859 & $>18$ & Prevalence, direct \& indirect cost & Chinese \\
\hline Liu et $\mathrm{a}^{30}$ & 2011 & Meizhou, Guangdong & Survey & 134 & $58-85$ & QoL & Chinese \\
\hline Wang et al ${ }^{\mid 3}$ & 2011 & China & Official statistics & & $\geq 40$ & Prevalence, mortality & English \\
\hline Fletcher et $\mathrm{al}^{32}$ & 2011 & $\begin{array}{l}\text { Brazil, China, Germany, } \\
\text { Turkey, UK, US }\end{array}$ & Survey & 2,426 & $45-67$ & QoL, direct \& indirect cost & English \\
\hline Yin et $\mathrm{a}^{33}$ & 2011 & China & Official statistics & 49,363 & $15-69$ & Prevalence, influencing factors & English \\
\hline $\mathrm{Guo}^{34}$ & 2010 & Guangzhou, Guangdong & Institutional data & 669 & & Direct \& indirect cost & Chinese \\
\hline Lou et $\mathrm{al}^{35}$ & 2010 & Xuzhou, Jiangsu & Survey & 383 & $34-84$ & YLL, direct \& indirect cost & Chinese \\
\hline $\mathrm{Lu}$ and $\mathrm{Li}^{36}$ & 2010 & Beijing & Survey & 61 & & QoL & Chinese \\
\hline Zhou et al ${ }^{37}$ & 2009 & China (rural) & Survey & 11,290 & $\geq 40$ & $\begin{array}{l}\text { Prevalence, influencing factors, } \\
\text { consultation rate, QoL }\end{array}$ & Chinese \\
\hline Zhou et al ${ }^{38}$ & 2009 & China & Survey & 20,245 & $\geq 40$ & QoL & Chinese \\
\hline Chen $^{39}$ & 2009 & Shanghai & Institutional data & 83 & $>40$ & Direct cost & Chinese \\
\hline An et $\mathrm{al}^{40}$ & 2009 & Xuzhou, Jiangsu & Survey & 383 & 62 & Direct cost & Chinese \\
\hline He et $\mathrm{al}^{4 !}$ & 2009 & China & Survey & 723 & $67 \pm 10$ & QoL, direct \& indirect cost & Chinese \\
\hline Zhu and $\mathrm{Cai}^{42}$ & 2009 & Beijing & Institutional data & 416 & & Direct cost & Chinese \\
\hline Hosgood et al ${ }^{43}$ & 2009 & Xuan Wei, Yunnan & Survey & 160 & & Influencing factors & English \\
\hline Jiang et $\mathrm{al}^{44}$ & 2008 & Hubei & Survey & $\mathrm{I}, 883$ & $>40$ & Prevalence, consultation rate & Chinese \\
\hline Cai et $\mathrm{al}^{45}$ & 2008 & $\begin{array}{l}\text { Kunming, Yunnan } \\
\text { (Suburban) }\end{array}$ & Official statistics & 335,622 & $>0$ & Influencing factors, mortality, YLL & English \\
\hline Shen et $\mathrm{al}^{46}$ & 2008 & Xuan Wei, Yunnan & Survey & 178 & & Influencing factors & English \\
\hline Zhang $^{47}$ & 2007 & Shandong & Survey & & & Direct \& indirect cost & Chinese \\
\hline Jiang et $\mathrm{al}^{48}$ & 2007 & Hubei & Survey & $\mathrm{I}, 883$ & $>40$ & Prevalence, influencing factors & Chinese \\
\hline Zhang et $\mathrm{a}^{49}$ & 2007 & Chengdu, Sichuan & Survey & 446 & & Direct cost & Chinese \\
\hline Zhang et a $\left.\right|^{50}$ & 2007 & Chengdu, Sichuan & Survey & 446 & $38-94$ & Consultation rate & Chinese \\
\hline$X u$ et $\mathrm{al}^{51}$ & 2007 & Nanjing & Survey & 29,319 & $\geq 35$ & Prevalence, influencing factors & English \\
\hline Liu et $\mathrm{a}^{52}$ & 2007 & Guangdong & Survey & 3,286 & $\geq 40$ & Prevalence, influencing factors & English \\
\hline Zhong et $\mathrm{a}^{53}$ & 2007 & China & Survey & 20,245 & $40-99$ & Prevalence, influencing factors & English \\
\hline Yang et al ${ }^{54}$ & 2006 & Beijing & Survey & 110 & $68-90$ & QoL & Chinese \\
\hline Cai and & 2006 & Kunming, Yunnan & Official statistics & 894,253 & $>0$ & Mortality, YLL & English \\
\hline \multicolumn{8}{|c|}{ Chongsuvivatwong ${ }^{55}$} \\
\hline Ren et $\mathrm{al}^{56}$ & 2002 & Chengdu, Sichuan & Survey & 205 & & Consultation rate, direct cost & Chinese \\
\hline
\end{tabular}

Abbreviations: DALY, disability-adjusted living years; YLL, years of life lost; YLD, years lost due to disability; QoL, quality of life. 
Table 4 Prevalence of COPD in China

\begin{tabular}{|c|c|c|c|c|c|c|c|c|}
\hline \multirow{2}{*}{$\begin{array}{l}\text { Publication } \\
\text { year }\end{array}$} & \multirow{2}{*}{$\begin{array}{l}\text { Study } \\
\text { region }\end{array}$} & \multirow{2}{*}{$\begin{array}{l}\text { Sample } \\
\text { size }\end{array}$} & \multirow{2}{*}{$\begin{array}{l}\text { Age } \\
\text { (years) }\end{array}$} & \multicolumn{5}{|c|}{ Prevalence (\%) } \\
\hline & & & & Overall & Female & Male & Urban & Rural \\
\hline 2015 & China $^{10}$ & & $>15$ & 3.90 & & & & \\
\hline 2015 & Heilongjiang ${ }^{\prime \prime}$ & 4,478 & $\geq 40$ & 7.30 & 6.50 & 8.60 & 6.00 & 8.80 \\
\hline 2014 & Xinjiang ${ }^{15}$ & 2,874 & $\geq 35$ & & & & & 7.50 \\
\hline 2014 & Yunnan $^{16}$ & 17,158 & $>18$ & 1.20 & 1.00 & 1.40 & & \\
\hline 2012 & Ningxia $^{23}$ & 4,626 & $\geq 40$ & 8.87 & 5.35 & 13.01 & 7.97 & 9.78 \\
\hline 2012 & Yunnan ${ }^{24}$ & 9,396 & $\geq 18$ & & & & & 1.41 \\
\hline 2011 & China $^{29}$ & 1,859 & $\geq 18$ & & & & 1.92 & \\
\hline 2011 & China $^{33}$ & 49,363 & $15-69$ & 2.20 & 2.40 & 3.40 & 2.50 & 3.10 \\
\hline 2009 & China $^{37}$ & 11,290 & $\geq 40$ & & & & & 8.80 \\
\hline 2007 & Hubei $^{48}$ & 1,883 & $\geq 40$ & & & & & 9.88 \\
\hline 2007 & Nanjing ${ }^{51}$ & 29,319 & $\geq 35$ & 5.90 & & & & \\
\hline 2007 & Guangdong ${ }^{52}$ & 3,286 & $>40$ & 9.40 & & & & \\
\hline 2007 & China $^{53}$ & 20,245 & $40-99$ & 8.20 & 5.10 & 12.40 & 7.80 & 8.80 \\
\hline
\end{tabular}

Another research conducted by the World Bank estimated that the number of projected cases of COPD in China would be $25,658,483$ in $2010,42,527,240$ in 2020 and $55,174,104$ in $2030 .^{31}$

\section{Consultation rate}

The diagnostic rate of COPD (number of patients diagnosed with COPD divided by the number of COPD cases found through epidemiology research) in China varies from $23.61 \%$ to $30.00 \%{ }^{23,37,44}$ The percentage of COPD patients receiving outpatient treatment is around $50 \%,{ }^{50,56}$ while the admission rate ranges between $8.78 \%$ and $35.60 \%{ }^{28,50,56}$ (Figure 2).
A national survey across seven provinces ${ }^{37}$ found that the regular medical treatment rate of COPD patients was only $7.9 \%$ which calls for the improvement of the prevention and management of COPD. There is still a large amount of unmet needs in health services among COPD patients in China.

\section{Risk factors of COPD}

A total of 13 studies analyzed the risk factors of COPD. Figure 3 shows the major factors and the number of studies that define them as risk factors of COPD in China. Tobacco exposure and biomass fuel/solid fuel usage are documented as two important risk factors of COPD, mentioned in

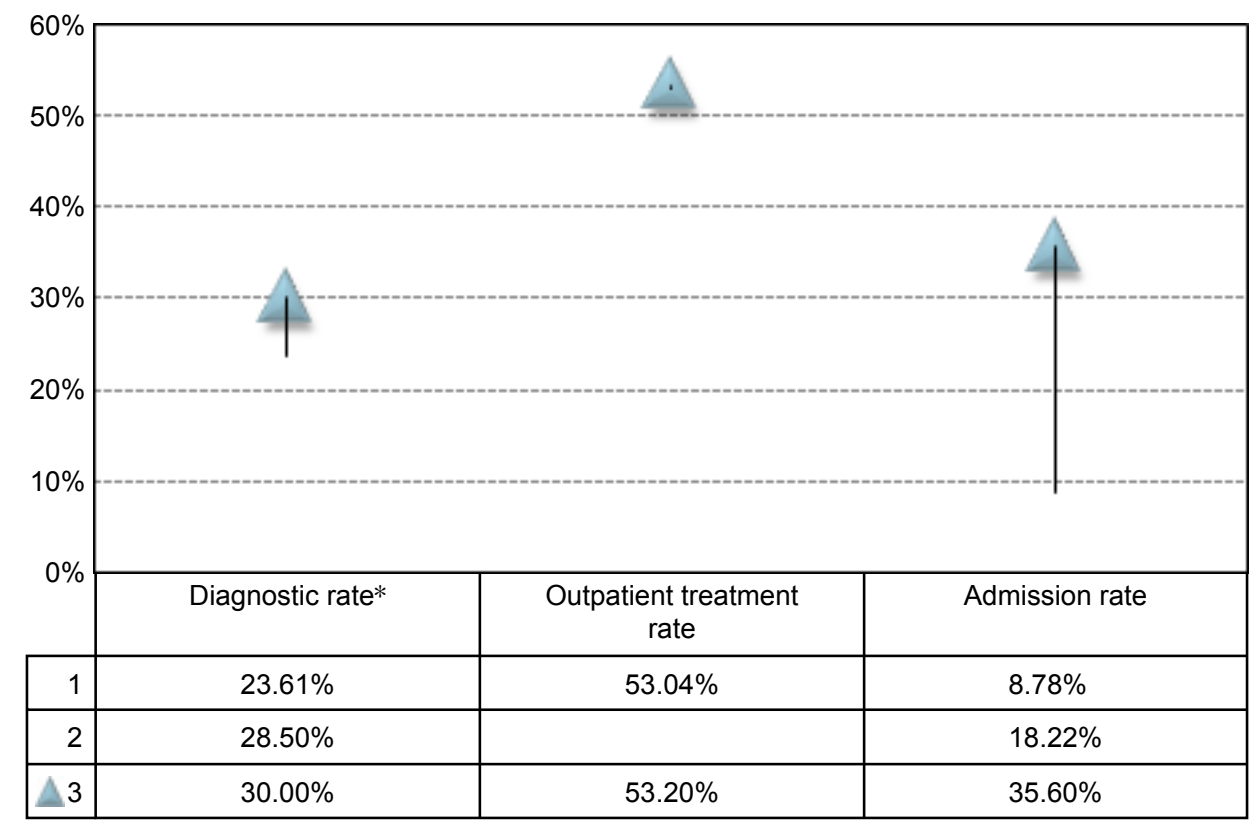

Figure 2 Consultation rate of COPD in China.

Note: *Diagnostic rate is defined by the number of patients who have been diagnosed with COPD in the past divided by the number of subjects recognized as COPD cases through epidemiology research. 


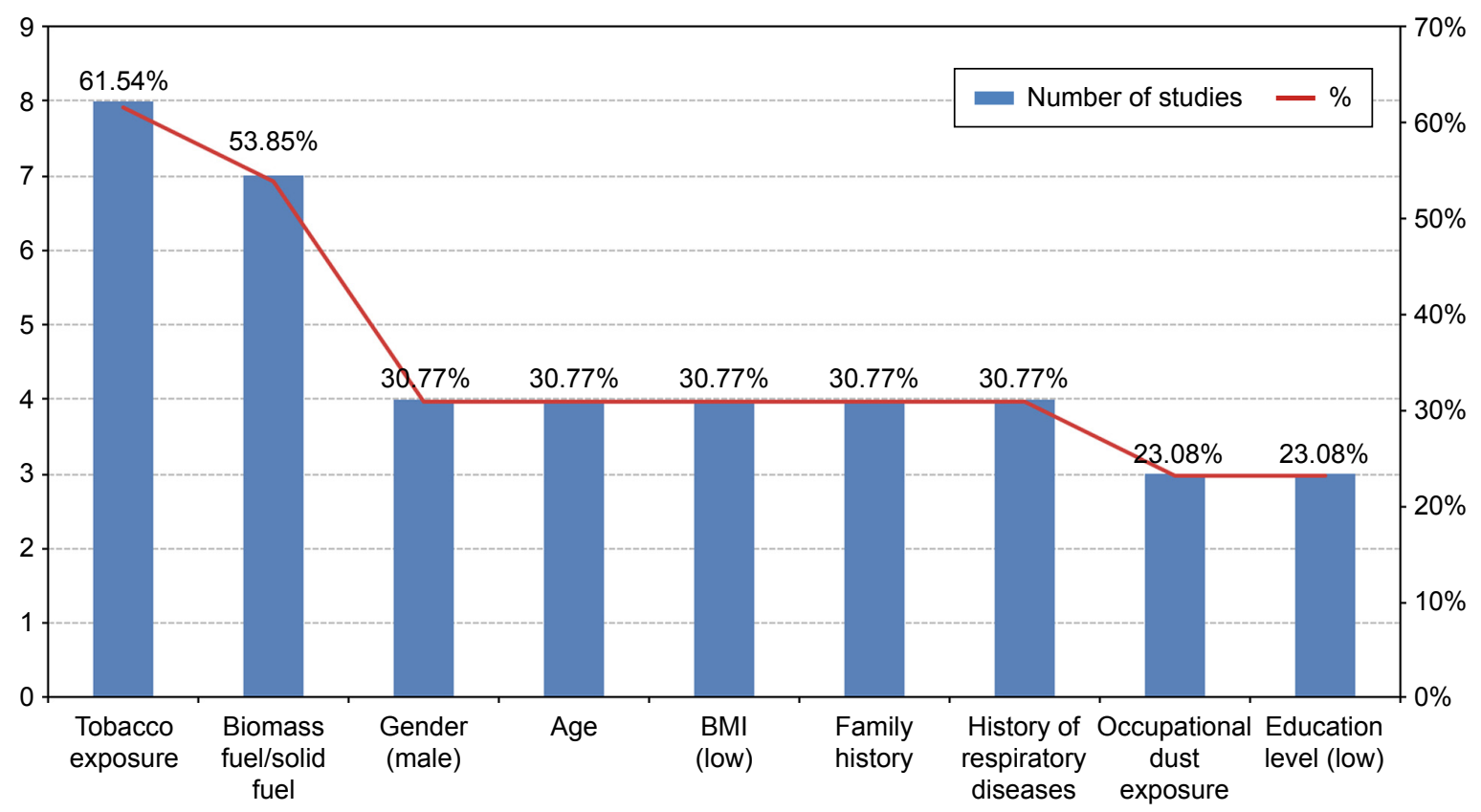

Figure 3 Risk factors of COPD in China.

eight (61.54\%) studies ${ }^{16,23,27,33,37,48,51,53}$ and seven (53.85\%) studies, ${ }^{11,27,37,45,48,52,53}$ respectively. Other major risk factors include gender, ${ }^{11,23,48,53}$ age, ${ }^{11,23,48,53}$ low BMI, ${ }^{15,23,48,53}$ family history, ${ }^{23,27,48,53}$ history of respiratory disease, ${ }^{11,23,48,53}$ occupational dust exposure, ${ }^{23,27,53}$ and low education level. ${ }^{11,33,53}$

Other risk factors include cardiovascular disease, ${ }^{11}$ lack of exercise and social support, ${ }^{27}$ low level of household income, ${ }^{33}$ frequency of cooking, ${ }^{48}$ having house remodelling in the past 5 years, ${ }^{48}$ and poor ventilation in the kitchen, ${ }^{53}$ which are not listed in the figure because of their low level of evidence strength; that is, they are mentioned by only one study.

Another case-control study ${ }^{46}$ conducted in Xuanwei, a region with high exposure to indoor smoky coal emissions, tested the association between single-nucleotide polymorphisms and COPD risk and concluded that polymorphisms in CSF2, IL8, and PTEN may have an effect on the pathogenesis of COPD.

\section{Mortality}

According to the Global Burden of Disease Study 2010, ${ }^{8}$ COPD ranked among the top three leading causes of death in China, causing 934,000 deaths $(534,000$ men and 400,000 women) in 2010.

The age-standardized mortality rate of COPD declined from $235.2 / 100,000$ in 1990 to $90.5 / 100,000$ in $2010 .{ }^{8}$ Another regional study reported a similar trend: ${ }^{18}$ the age-standardized mortality rate of COPD in Jinshan District, Shanghai (located in eastern China) declined from 219.43/100,000 in 1985 to $45.66 / 100,000$ in 2011 , yet the level of premature mortality of COPD in China is still worse than the average outcomes of the member coutries of Group of Twenty (G20). ${ }^{22}$

Another two studies reported the level of COPD mortality in Kunming, Yunnan Province which is located in the southwest of China: the age-standardized mortality rate of COPD in 2003 was the highest in rural areas (184.4/100,000), followed by suburban $(129.5 / 100,000)$, and then urban areas $(51.2 / 100,000),{ }^{55}$ while the crude mortality rate in rural Kunming was $65.67 / 100,000$ in $2010 .^{24}$

Lin et $\mathrm{al}^{9}$ suggested that $\sim 65$ million people may die from COPD from 2003 to 2033 , accounting for $19 \%$ of all deaths over this period, unless the smoking rate and solid-fuel usage are controlled.

\section{DALY}

Combining premature mortality (YLL) and disability (YLD) together in terms of DALYs provides an overall picture of the disease burden of COPD in China. According to the Global Burden of Disease Study 2010, a total number of 16,723,800 DALYs were caused by COPD, ranking among the top $10 .{ }^{22}$ The age-standardized rate of DALY declined from 4,120.1/100,000 in 1990 to $1,575.9 / 100,000$ in $2010 .{ }^{10}$ Another regional study reported that the rate of DALY in rural Kunming, Yunnan Province, was 602/100,000 (673/100,000 among men and 526/100,000 among women). ${ }^{24}$

COPD also remained one of the leading causes of YLL, ${ }^{10}$ causing 12,946,000 YLL. Age-standardized YLL rates of COPD decreased from 3,756.9/100,000 in 1990 to $1,235.6 / 100,000$ in 2010, ranked 18 in 2010 among the member countries of G20, worse than the average outcome. ${ }^{22}$ 
Table 5 Total disease cost of COPD in China*

\begin{tabular}{|c|c|c|c|c|c|c|c|}
\hline $\begin{array}{l}\text { Publication } \\
\text { year }\end{array}$ & $\begin{array}{l}\text { Study } \\
\text { region }\end{array}$ & $\begin{array}{l}\text { Sample } \\
\text { size }\end{array}$ & $\begin{array}{l}\text { Direct cost } \\
\text { (per capita } \\
\text { per year, USD) }\end{array}$ & $\begin{array}{l}\text { Direct medical } \\
\text { cost (per capita } \\
\text { per year, USD) }\end{array}$ & $\begin{array}{l}\text { Direct non-medical } \\
\text { cost (per capita } \\
\text { per year, USD) }\end{array}$ & $\begin{array}{l}\text { Indirect cost } \\
\text { (per capita } \\
\text { per year, USD) }\end{array}$ & $\begin{array}{l}\text { Total disease } \\
\text { cost (per capita } \\
\text { per year, USD) }\end{array}$ \\
\hline 2015 & Ningbo ${ }^{12}$ & 803 & & & & & 685 \\
\hline 2013 & Chengdu ${ }^{17}$ & 83 & 1,930 & & & 396 & \\
\hline 2012 & Rural Yunnan ${ }^{24}$ & 9,396 & 884 & & & 20 & \\
\hline 2011 & China ${ }^{29}$ & 1,859 & 726 & & & 306 & $\mathrm{I}, 033$ \\
\hline 2010 & Xuzhou ${ }^{28}$ & 383 & & 298 & & & \\
\hline 2009 & Shanghai ${ }^{39}$ & 83 & & $\mathrm{I}, 323$ & & & \\
\hline 2009 & China $^{41}$ & 723 & & 3,565 & 477 & & \\
\hline 2007 & Shandong ${ }^{47}$ & 150 & & 358 & 136 & 783 & $\mathrm{I}, 277$ \\
\hline 2007 & Chengdu $^{49}$ & 446 & 499 & & & & \\
\hline 2002 & Chengdu ${ }^{56}$ & 205 & & 729 & & & \\
\hline 2014 & Yunnan ${ }^{16}$ & 17,158 & & 1,657 & 109 & 22 & $\mathrm{I}, 787$ \\
\hline 2011 & Shanghai ${ }^{32}$ & 398 & & 72 & & 77 & \\
\hline
\end{tabular}

Notes: *All Chinese currency in the tables of this section are adjusted to comparable prices to 2013, according to the Residence Consumption Index (http://data.stats.gov. cn/easyquery.htm?cn COI) and converted to USD according to the exchange rate in 2013 (6.1932 RMB=I USD).

In Kunming, Yunnan Province, COPD was ranked second among the causes of YLL in urban and suburban areas and ranked top in rural areas in 2003..$^{55}$

In Xuzhou, Jiangsu Province, COPD caused 1.76 years of potential life lost per patient among men and 1.18 among women in $2007 .{ }^{27}$ In Shanghai Jinshan District, over 27 years, from 1985 to 2011, the standardized rate of years of potential life lost decreased from $1,543 / 100,000$ to $140 / 100,000 .{ }^{18}$

\section{Cost of illness}

\section{Total disease cost}

A total of 12 studies analyzed the disease cost (Table 5). The direct cost of COPD ranges from 499 to 1,930 USD per capita per year. The direct medical cost of COPD ranges from 72 to 3,565 USD per capita per year, accounting for $33.33 \%-118.09 \%$ of local average annual income. ${ }^{28,47}$ The indirect cost ranges from 20 to 783 USD per capita per year, with the total disease cost being around 700-1,800 USD. The study conducted in Chengdu suggested that the direct cost of COPD accounted for $22.98 \%$ of patients' annual income, while indirect cost accounted for $4.72 \% .{ }^{17}$

A human capital approach is usually adopted in calculating the indirect cost, while there is disagreement concerning the loss of working time due to COPD. A study in rural Yunnan found that COPD patients were incapable of working for about 150 days each year, while their family members were unable to work for 59 days each year, ${ }^{28}$ hence, the lifetime indirect cost of COPD was 3,414 USD per capita when the method of YPLL was applied. Two other research studies brought forth similar conclusions that COPD patients were prevented from work for an average time of 17 days ${ }^{41}$ and 15 days per year, ${ }^{29}$ indicating high economic impact of COPD caused by loss in productivity.

In terms of lifetime indirect loss due to COPD, a multinational evaluation claimed the average losses in China to be the lowest (678 USD ${ }^{32}$ ) among five countries. Another research conducted in Guangzhou concluded that the lifetime loss was 7,256 USD per capita. ${ }^{34}$

Only one study reported the intangible cost of COPD: 1,168 USD per capita per year in rural Yunnan. ${ }^{24}$

\section{Outpatient and inpatient expenditure}

The results of hospitalization costs of COPD vary largely among different studies. Hospital-based studies usually lead to higher hospitalization expenses, as shown in Table 6 . Nonetheless, researchers consistently report that inpatient services account for a larger proportion of total disease

Table 6 Outpatient and hospitalization expenditure of COPD in China

\begin{tabular}{|c|c|c|c|c|c|}
\hline $\begin{array}{l}\text { Publication } \\
\text { year }\end{array}$ & $\begin{array}{l}\text { Study } \\
\text { region }\end{array}$ & $\begin{array}{l}\text { Sample } \\
\text { size }\end{array}$ & $\begin{array}{l}\text { Outpatient } \\
\text { expenditure (per } \\
\text { capita per year) (USD) }\end{array}$ & $\begin{array}{l}\text { Hospitalization } \\
\text { expenses (per } \\
\text { capita per year) (USD) }\end{array}$ & Features \\
\hline 2015 & Beijing $^{13}$ & 1,638 & & 4,220 & Hospital based \\
\hline 2010 & Guangzhou ${ }^{34}$ & 669 & & 5,611 & Hospital based \\
\hline 2009 & Beijing ${ }^{42}$ & 416 & & 20,295 & Hospital based \\
\hline 2002 & Chengdu ${ }^{56}$ & 205 & 202 & 338 & Community based \\
\hline 2014 & Rural Yunnan ${ }^{16}$ & 17,158 & 74 & I,332 & Community based \\
\hline
\end{tabular}




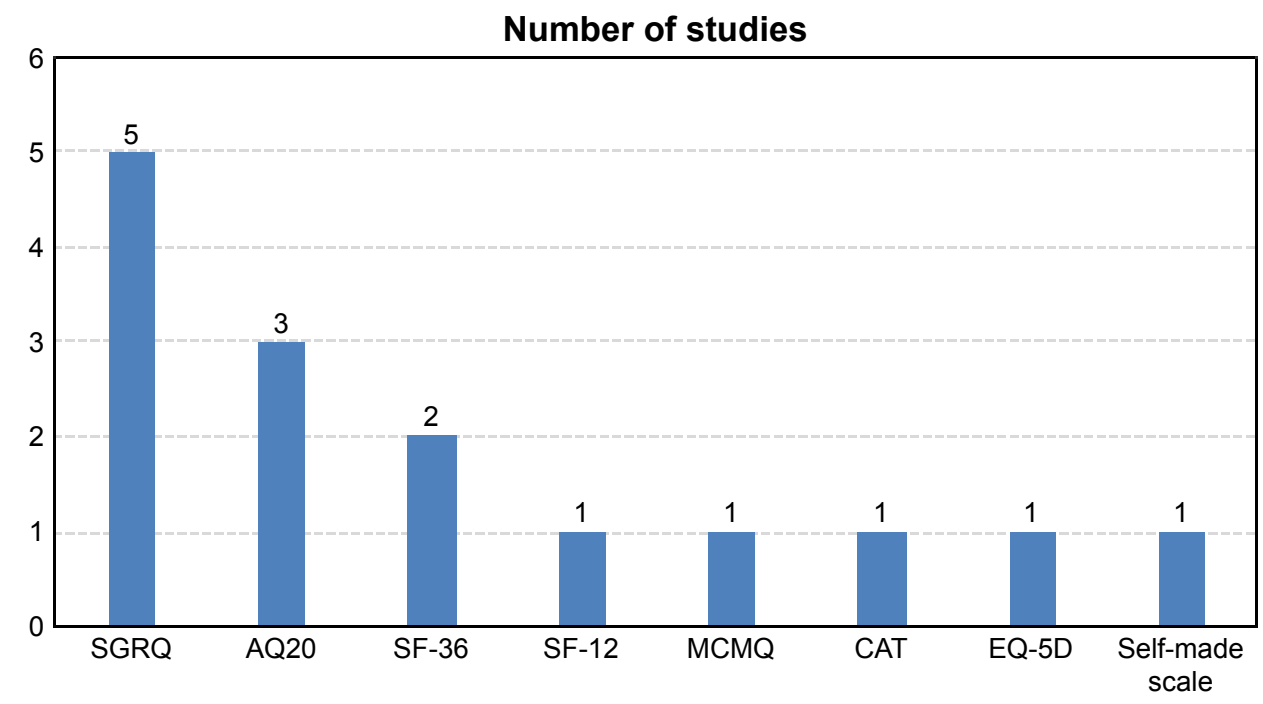

Figure 4 Major scales used for QoL assessment of COPD patients.

Abbreviations: SGRQ, Saint George Respiratory Questionnaire; AQ20, Airways Questionnaire 20; SF-12, I2-item short-form health survey questionnaire; MCMQ, Medical Coping Modes Questionnaire; CAT, COPD Assessment Test; SF-36, 36-item Short Form Survey Instrument; EQ-5D, EuroQol Five-Dimensional Questionnaire.

cost. The research conducted in Ningbo, Zhejiang Province, suggested that costs of inpatient services accounted for $77 \%$ of COPD-related medical costs. ${ }^{12}$

\section{Main reason for cost}

In terms of the influence factors of cost, the most frequently mentioned factors are number of visits/admissions s $^{13,17,47,49,56}$ and severity of the disease. . $^{3,39,49,56}$

Researchers found that patients with high-income levels usually generate higher medical costs and that those unemployed often bear lower economic burden. In terms of insurance type, patients with free medical services (a type of insurance for public servants where most of their medical expenditures are paid by the state) usually have higher medical costs. ${ }^{56}$

Yet contradictory perspectives on the influence of patient sources on medical costs exist. Some believe that local patients bear higher medical costs because of the relatively higher income level and sound insurance system, ${ }^{13}$ while others hold the opposite view that patients from nonlocal areas have undergone heavier economic burden due to the severity of their diseases when they need to go to a major city for treatment. ${ }^{34}$

Other influencing factors include length of stay, ${ }^{13,34}$ age, ${ }^{40,47}$ status of smoking, ${ }^{47}$ whether undertaking surgery, ${ }^{34}$ marital state, ${ }^{34}$ attitude toward the disease, ${ }^{49}$ and physical exercise. ${ }^{17}$

\section{QoL}

A total of 13 studies are included in the analysis of scales used for QoL assessment (Figure 4). The most commonly used scales include Saint George Respiratory Questionnaire, ${ }^{20,21,27,36,41}$ Airways Questionnaire 20 (AQ20), ${ }^{14,25,30} 12$-item short-form health survey questionnaire, ${ }^{38}$ Medical Coping Modes Questionnaire, ${ }^{25}$ COPD Assessment Test, ${ }^{26}$ EuroQol FiveDimensional Questionnaire, ${ }^{32}$ and their revised versions. One of the studies established a self-made scale to assess the QoL of COPD patients. ${ }^{54}$

An overall conclusion is that the quality assessment scores are lower among COPD patients, and four studies report significant results when compared with non-COPD patients. In two studies applying AQ20, the QoL of $56.1 \%-61.9 \%$ of COPD patients are in the lower and poorer level. Another two studies reported higher likelihood of COPD patients to have depression. ${ }^{14,26}$ The status of QoL is worse among COPD patients than in non-COPD patients, and they are at higher risk of having depression.

\section{Conclusion}

The prevalence of COPD shows a wide range of variation throughout the nation. An overall trend is that the prevalence rate is higher among men and in rural areas. The diagnostic rate, outpatient treatment rate, and admission rate of COPD are relatively low, indicating considerable under-treatment and unmet medical needs of COPD in China. Tobacco exposure and biomass fuel/solid fuel usage are documented as two important risk factors of COPD. The results of economic burden of COPD vary largely due to differences in study designs and heterogeneity of sample characteristics. While various studies reported different degrees of productivity loss in both COPD patients and their relatives, there is still an urgent need to understand the overall cost of COPD in China through well-designed research on disease burden. 
In view of the high smoking rate and considerable concerns related to air pollution and smog in China, as well as the large gap of unmet medical needs, countermeasures need to be taken to improve disease prevention and management to reduce disease burdens raised by COPD.

\section{Acknowledgment}

The abstract of this work was submitted to International Society for Pharmacoeconomics and Outcomes Research 21st Annual International Meeting as a poster presentation and was published in Value in Health in 2016.

\section{Disclosure}

The authors report no conflicts of interest in this work.

\section{References}

1. Rabe KF, Hurd S, Anzueto A, et al. Global Initiative for Chronic Obstructive Lung Disease. Global strategy for the diagnosis, management, and prevention of chronic obstructive pulmonary disease: GOLD executive summary. Am J Respir Crit Care Med. 2007;176(6):532-555.

2. Mathers CD, Loncar D. Projections of global mortality and burden of disease from 2002 to 2030. PLoS Med. 2006;3(11):e442.

3. Halbert RJ, Natoli JL, Gano A, Badamgarav E, Buist AS, Mannino DM. Global burden of COPD: systematic review and meta-analysis. Eur Respir J. 2006;28(3):523-532.

4. Fang X, Wang X, Bai C. COPD in China: the burden and importance of proper management. Chest. 2011;139(4):920-929.

5. Rostom A, Dube C, Cranney A, et al. Appendix D. Quality Assessment Forms. Celiac disease. Evidence Reports/Technology Assessments, No. 104. Rockville, MD: Agency for Healthcare Research and Quality (US); 2004. Available from: https://www.ncbi.nlm.nih.gov/books/ NBK35156/. Accessed April 8, 2018.

6. Stang A. Critical evaluation of the Newcastle-Ottawa scale for the assessment of the quality of nonrandomized studies in meta-analysis. Eur J Epidemiol. 2010;25(9):603-605.

7. Drummond MF, Sculpher MJ, Torrance GW, O'Brien BJ, Stoddart GL. Methods for the Economic Evaluation of Health Care Programmes. Third edition. Beijing: People's Medical Publishing House; 2008. Chinese.

8. Xu G, Zhang Z, Lv Q, et al. NSFC health research funding and burden of disease in China. PLoS One. 2014;9:e111458.

9. Lin HH, Murray M, Cohen T, Colijn C, Ezzati M. Effects of smoking and solid-fuel use on COPD, lung cancer, and tuberculosis in China: a timebased, multiple risk factor, modelling study. Lancet. 2008;372(9648) 1473-1483.

10. Yin P, Wang LJ, Liu SW, et al. The disease burden of chronic obstructive pulmonary disease among people aged over 15 years in 1990 and 2010 in China. Zhonghua Yu Fang Yi Xue Za Zhi. 2015;49(4): 334-338. Chinese.

11. Han R, Zou JH, Shen X, et al. The risk factors of chronic obstructive pulmonary disease in Heilongiiang province. Zhonghua Yu Fang $Y i$ Xue Za Zhi. 2015;38(2):93-98. Chinese.

12. Shi BJ, Zhang T, Cui J, Wang Y, Li H. Direct economic burden of 803 patients with chronic obstructive pulmonary disease and influencing factors in Ningbo. Dis Surveill. 2015;30(4):300-304. Chinese.

13. Huang J. Analysis on direct economic burden of hospitalized patients with COPD and its influencing factors in a three-level hospital in Beijing. Med Soc. 2015;28(7):19-22. Chinese.

14. Chen HJ, Bian HY. Analysis on quality of life and its influencing factors in patients with stable chronic obstructive pulmonary disease. Pract Prev Med. 2015;22(4):470-471. Chinese.

15. Zhu LL, Fang MQ, Zhu J, et al. Correlation study of body mass index with morbidity rate of chronic obstructive pulmonary disease in parts of Xinjiang. Clin Med. 2014;34(8):1-4. Chinese.
16. Cai L, Cui W, He J, Wu X. The economic burden of smoking and secondhand smoke exposure in rural South-West China. J Asthma. 2014; 51(5):515-521.

17. $\mathrm{Xu} \mathrm{M}, \mathrm{He} \mathrm{CP}$, Luo Y, et al. Economic burden and influence factors of chronic obstructive pulmonary disease patients in Chenghua District. J Prev Med Inf. 2013;29(10):889-892. Chinese.

18. Zhu XY, Gao X, Qiao GL. Mortality and the trend of YPLL of COPD in Jinshan District of Shanghai City from 1985-2011. Occup Health. 2013;29(11):1292-1294. Chinese.

19. An XJ, Nie QR, Deng GF. The correlational study of severity and life quality of stable phase chronic obstructive pulmonary disease patients. Chin J Soc Med. 2013;30(5):339-341. Chinese.

20. Fang Y, Zhang M, Wang L. Analysis on quality of life of patients with chronic obstructive pulmonary disease and its influencing factors. Chin Nurs Res. 2013;27(23):2450-2452. Chinese.

21. Jiang M. Application of COPD-specific version of the St George's Respiratory Questionnaire in evaluating quality of life among COPD patients in Guangzhou. Chin J Health Stat. 2013;30(6):808-811. Chinese.

22. Yang G, Wang Y, Zeng Y, et al. Rapid health transition in China, 1990-2010: findings from the Global Burden of Disease study 2010. Lancet. 2013;381(9882):1987-2015.

23. Qiu J. Prevalence of chronic obstructive pulmonary disease in Ningxia Province of China. Ningxia Medical University; 2012. Chinese. Available from: http://www.wanfangdata.com.cn/details/detail.do? type $=$ degree\&id=D225251. Accessed April 8, 2018.

24. Mao HY, Cai L, Shu ZK, et al. Analysis of prevalence and economic burden of chronic obstructive pulmonary disease in rural residents of Yunnan Province. Chin J Prev Control Chronic Noncommun Dis. 2012; 20(3):244-246. Chinese.

25. Li RH. Quality of life and coping style in patients with chronic obstructive pulmonary disease. Zhongshan University; 2008:71-74. Chinese. Available from: http://www.wanfangdata.com.cn/details/ detail.do?_type=degree\&id=D124487. Accessed April 8, 2018.

26. He YQ, Xu CQ, Zheng YL, et al. Quality of life and its related factors in patients of stable chronic obstructive pulmonary disease. Chin J Gen Pract. 2012;11(11):860-862. Chinese.

27. Lou P, Zhu Y, Chen P, et al. Vulnerability of patients with chronic obstructive pulmonary disease according to gender in China. Int $J$ Chron Obstruct Pulmon Dis. 2012;7:825-832.

28. Lou P, Zhu Y, Chen P, et al. Vulnerability, beliefs, treatments and economic burden of chronic obstructive pulmonary disease in rural areas in China: a cross-sectional study. BMC Public Health. 2012; 12:287.

29. Xu DB, Li HC, Ma AX. Study on the costs of chronic obstructive pulmonary disease. Chin J Pharm Econ. 2011;6(1):18-26. Chinese.

30. Liu YW, Cai DX, Zhong W, et al. Evaluation and analysis on quality of life and influencing factors of patients with chronic obstructive pulmonary disease. Chin Med Herald. 2011;8(10):146-147. Chinese.

31. Wang S, Marquez P, Langenbrunner J, et al. Toward a healthy and harmonious life in China: stemming the rising tide of non-communicable diseases. Washington, DC: World Bank. 2011:1-48.

32. Fletcher MJ, Upton J, Taylor-Fishwick J, et al. COPD uncovered: an international survey on the impact of chronic obstructive pulmonary disease [COPD] on a working age population. BMC Public Health. 2011;11:612.

33. Yin P, Zhang M, Li Y, et al. Prevalence of COPD and its association with socioeconomic status in China: findings from China Chronic Disease Risk Factor Surveillance 2007. BMC Public Health. 2011;11:586.

34. Guo ZQ. A study on economic burden for hospitalized patients with COPD. Guangzhou Medical College; 2010. Chinese. Available from: http://www. wanfangdata.com.cn/details/detail.do?_type=degree\&id=D124487. Accessed April 8, 2018.

35. Lou PA, Yu JX, Zhang L, et al. Analysis on economic burden of COPD patients in Tongshan County. Chin J Dis Control Prev. 2010;14(11): 1129-1131. Chinese.

36. Lu DM, Li L. Survey of the quality of life and social supports of patients with chronic obstructive pulmonary disease in community. J Nurs Adm. 2010;10(12):850-851. Chinese. 
37. Zhou YM, Wang C, Yao WZ, et al. Current status of prevention and management of chronic obstructive pulmonary disease in rural area in China. Chin J Intern Med. 2009;48(5):358-361. Chinese.

38. Zhou YM, Wang C, Yao WZ, et al. The quality of life of patients with chronic obstructive pulmonary disease and correlated factors. Zhonghua Jie He He Hu Xi Za Zhi. 2009;32(4):248-252. Chinese.

39. Chen SJ. The economic burden of chronic obstructive pulmonary disease (COPD) in Shanghai and the feasibility of 3D reconstruction using low-dose CT scan in diagnosis and classification of COPD. Fudan University; 2009. Chinese. Available from: http://www.wanfangdata. com.cn/details/detail.do?_type $=$ degree\&id=Y1967586. Accessed April 8, 2018.

40. An XH, Lou PA, Yu JX, et al. Research on direct economic burden of chronic obstructive pulmonary disease in community of Xuzhou City. Chin J School Doctor. 2009;23:505. Chinese.

41. He QY, Zhou X, Xie CM, et al. Impact of chronic obstructive pulmonary disease on quality of life and economic burden in Chinese urban areas. Zhonghua Jie He He Hu Xi Za Zhi. 2009;32(4):253-257. Chinese.

42. Zhu ML, Cai BQ. Costs of the last hospitalization for patients with acute exacerbation of chronic obstructive pulmonary disease and patients with lung cancer. Zhonghua Jie He He Hu Xi Za Zhi. 2009;32(4): 258-261. Chinese.

43. Hosgood HR, Menashe I, He X, et al. PTEN identified as important risk factor of chronic obstructive pulmonary disease. Respir Med. 2009; 103(12):1866-1870.

44. Jiang RG, Luo DS, Huang CP, et al. Analysis on status of chronic obstructive pulmonary disease in rural population. Mod Prev Med. 2008;35(3):561-562, 565. Chinese.

45. Cai L, Chongsuvivatwong V, Geater A. Changing pattern of premature mortality burden over 6 years of rapid growth of the economy in suburban south-west China: 1998-2003. Public Health. 2008;122(5): $478-486$.

46. Shen M, Vermeulen R, Chapman RS, et al. A report of cytokine polymorphisms and COPD risk in Xuan Wei, China. Int J Hyg Environ Health. 2008;211(3-4):352-356.
47. Zhang CY. The study of the economic burden on Chinese rural COPD patients. Shandong University; 2007. Chinese. Available from: http://www. wanfangdata.com.cn/details/detail.do?_type=degree\&id=Y1066432. Accessed April 8, 2018.

48. Jiang RG, Luo DS, Huang CP, et al. Study on the prevalence rate and risk factors of chronic obstructive pulmonary disease in rural community population in Hubei province. Chin J Epidemiol. 2007;28(10):976-979. Chinese.

49. Zhang B, Zhang Y, Yang JY, et al. Analysis on direct economic burden of community COPD patients and its influence factors in Chengdu. J Hyg Res. 2007;36(6):706-710. Chinese.

50. Zhang B, Zhang Y, Liu HC, et al. Factors influencing the use of health care services from patients with COPD in Chengdu. J Sichuan Univ. 2007;38(2):316-320. Chinese.

51. Xu F, Yin X, Shen H, et al. Better understanding the influence of cigarette smoking and indoor air pollution on chronic obstructive pulmonary disease: a case-control study in Mainland China. Respirology. 2007;12(6):891-897.

52. Liu S, Zhou Y, Wang X, et al. Biomass fuels are the probable risk factor for chronic obstructive pulmonary disease in rural South China. Thorax. 2007;62(10):889-897.

53. Zhong N, Wang C, Yao W, et al. Prevalence of chronic obstructive pulmonary disease in China: a large, population-based survey. Am J Respir Crit Care Med. 2007;176(8):753-760.

54. Yang J, Hou HR, Gao Y. Investigation and analysis on the quality of life and influence factors in patients with COPD. J Nurs Adm. 2006; 6(3):1-2. Chinese.

55. Cai L, Chongsuvivatwong V. Rural-urban differentials of premature mortality burden in south-west China. Int J Equity Health. 2006;5:13.

56. Ren JP, Li H, Mao ZZ, et al. The economic burden of the COPD and its factor analysis. Health Econ Res. 2002;9(10):16-17. Chinese. 


\section{Supplementary material}

Table SI Quality assessment results of included studies

\begin{tabular}{ll}
\hline No Article title & Changing pattern of premature mortality burden over 6 years of rapid growth of the economy in suburban south-west China: \\
\hline I & R98-2003 \\
2 & Rural-urban differentials of premature mortality burden in south-west China \\
3 & Rapid health transition in China, I990-20I0: findings from the Global Burden of Disease study 20I0 \\
4 & NSFC health research funding and burden of disease in China \\
5 & Toward a healthy and harmonious life in China: stemming the rising tide of non-communicable diseases \\
6 & Vulnerability of patients with chronic obstructive pulmonary disease according to gender in China \\
7 & Vulnerability, beliefs, treatments and economic burden of chronic obstructive pulmonary disease in rural areas in China: \\
8 & $\begin{array}{l}\text { a cross-sectional study } \\
9\end{array}$ COPD uncovered: an international survey on the impact of chronic obstructive pulmonary disease [COPD] on a working age
\end{tabular}
population

10 Better understanding the influence of cigarette smoking and indoor air pollution on chronic obstructive pulmonary disease: a case-control study in Mainland China

II Biomass fuels are the probable risk factor for chronic obstructive pulmonary disease in rural South China

I3 PTEN identified as important risk factor of chronic obstructive pulmonary disease

I4 Effects of smoking and solid-fuel use on COPD, lung cancer, and tuberculosis in China: a time-based, multiple risk factor, modelling study

I5 Prevalence of chronic obstructive pulmonary disease in Ningxia Province of China (in Chinese)

B

A

B

B

B

6 The economic burden of chronic obstructive pulmonary disease (COPD) in Shanghai and the feasibility of 3D reconstruction using low-dose CT scan in diagnosis and classification of COPD (in Chinese)

17 The study of the economic burden on Chinese rural COPD patients (in Chinese)

I8 A study on economic burden for hospitalized patients with COPD (in Chinese)

19 The risk factors of chronic obstructive pulmonary disease in Heilongjiang province (in Chinese)

20 Study on the prevalence rate and risk factors of chronic obstructive pulmonary disease in rural community population in Hubei province (in Chinese)

21 Correlation study of body mass index with morbidity rate of chronic obstructive pulmonary disease in parts of Xinjiang (in Chinese)

22 Analysis on status of chronic obstructive pulmonary disease in rural population (in Chinese)

24 Direct economic burden of 803 patients with chronic obstructive pulmonary disease and influencing factors in Ningbo (in Chinese)

25 The disease burden of chronic obstructive pulmonary disease among people aged over I5 years in 1990 and 2010 in China (in Chinese)

26 Analysis on direct economic burden of hospitalized patients with COPD and its influencing factors in a three-level hospital in Beijing (in Chinese)

27 Analysis on direct economic burden of community COPD patients and its influence factors in Chengdu (in Chinese)

28 Research on direct economic burden of chronic obstructive pulmonary disease in community of Xuzhou City (in Chinese)

29 Current status of prevention and management of chronic obstructive pulmonary disease in rural area in China (in Chinese)

30 Impact of chronic obstructive pulmonary disease on quality of life and economic burden in Chinese urban areas (in Chinese)

31 Costs of the last hospitalization for patients with acute exacerbation of chronic obstructive pulmonary disease and patients with lung cancer (in Chinese)

32 The economic burden of the COPD and its factor analysis (in Chinese)

33 Analysis of prevalence and economic burden of chronic obstructive pulmonary disease in rural residents of Yunnan Province (in Chinese)

34 Economic burden and influence factors of chronic obstructive pulmonary disease patients in Chenghua District (in Chinese)

35 Mortality and the trend of YPLL of COPD in Jinshan District of Shanghai City from 1985-20II (in Chinese)

36 Factors influencing the use of health care services from patients with COPD in Chengdu (in Chinese)

37 Study on the costs of chronic obstructive pulmonary disease (in Chinese)

38 The correlational study of severity and QoL of stable phase chronic obstructive pulmonary disease patients (in Chinese)

39 Analysis on quality of life and its influencing factors in patients with stable chronic obstructive pulmonary disease (in Chinese)

40 Analysis on quality of life of patients with chronic obstructive pulmonary disease and its influencing factors (in Chinese) 
Table SI (Continued)

\begin{tabular}{lll}
\hline No & Article title & Quality \\
\hline 41 & Investigation and analysis on the quality of life and influence factors in patients with COPD (in Chinese) \\
42 & Quality of life and coping style in patients with chronic obstructive pulmonary disease (in Chinese) \\
43 & Evaluation and analysis on quality of life and influencing factors of patients with chronic obstructive pulmonary disease (in Chinese) & B \\
44 & Quality of life and its related factors in patients of stable chronic obstructive pulmonary disease (in Chinese) \\
45 & Survey of the quality of life and social supports of patients with chronic obstructive pulmonary disease in community (in Chinese) & B \\
46 & Application of COPD-specific version of the St George's Respiratory Questionnaire in evaluating quality of life among COPD & B \\
47 & Patients in Guangzhou (in Chinese) & The quality of life of patients with chronic obstructive pulmonary disease and correlated factors (in Chinese)
\end{tabular}

\section{Publish your work in this journal}

The International Journal of COPD is an international, peer-reviewed journal of therapeutics and pharmacology focusing on concise rapid reporting of clinical studies and reviews in COPD. Special focus is given to the pathophysiological processes underlying the disease, intervention programs, patient focused education, and self management protocols.

\section{Dovepress}

This journal is indexed on PubMed Central, MedLine and CAS. The manuscript management system is completely online and includes a very quick and fair peer-review system, which is all easy to use. Visit $\mathrm{http}: / / \mathrm{www}$.dovepress.com/testimonials.php to read real quotes from published authors. 